\title{
Factors Influencing Patients Perception of Nurses Respect for Their Dignity in a Public Hospital in Calabar, Nigeria
}

\author{
Ella, R.E ${ }^{1}$. Samson-Akpan P. $E^{2}$., Mgbekem, M. $A^{3}$., Edet, $G^{4}$ \\ Department of Nursing Science, Faculty of Allied Medical Sciences, College of Medicine, \\ University of Calabar, Cross River State, Nigeria
}

\begin{abstract}
Background: Hospitalization create a dependency on others (especially nurses) for basic needs, this dependency threatens dignity and negatively affects the overall well being of a patient. Patients' perceived satisfaction with respect for their dignity by nurses is an indicator to evaluate quality nursing care. Little is known about factors that influence patients' perception of nurses' respect for their dignity in Calabar, Cross River State, Nigeria. The study was undertaken to examine in-patients' perception of nurses respect for their dignity. Methods: A cross sectional descriptive design was used. Purposive sampling technique was adopted to select a sample of 84 patients from six wards. A self developed structured questionnaire divided into four sections: socio-demographic characteristics, 'patients' perception of nurses' effective communication' 'patients' perception of their participation in decision making' 'patients' perception individualized care' was used to elicit information. Data was analyzed using simple proportion and Chi square statistics was to test the relationship between variables. Results: Most respondents 54(64.29\%) were between ages 20-30years, $54(64.29 \%)$ were females, most of the respondents 47 (55.99\%) were married, while 48(57.15\%) had university education. and all respondents had above I week hospitalization. The percentages of positive responses (respected dignity perception) were more frequent than negative (not respected dignity perception) in the sections of 'effective communication' and 'participation in decision making' while the section on 'individualized care' had higher percentage negative responses (un respected dignity perception). Further result showed a statistically significant relationship between nurses effective communication and patients positive perception of their dignity with cal $x^{2}=23.216$, crit $x^{2}=9.49$, df $1, P<0.05$, and between patients participation in decision making and their perception of nurses respect for their dignity with cal $x^{2}=12.734$, crit $x^{2}=9.49$, df $1 P<0.05$.
\end{abstract}

Conclusion: Dignity was not completely maintained according to the standards expected by patients. Training on communication skills, nursing ethics and holistic care should be strengthened.

Keywords: Nurses respect for patients' dignity, Effective communication, Decision making, Individualized care.

\section{BACKGROUND OF THE STUDY}

Impaired health, older age, hospitalization and illness create a dependency on others (especially nurses) for basic needs. This dependency threatens (reduces a person's ability to maintain and protect) dignity and negatively affects the overall well being of a patient (Whitehead \& Wheeler 2008b,). Respect for, and maintenance of patients' dignity by nurses can contribute to the 'emotional comfort' that may assist recovery. Observations show that respect for patients' dignity and values are given little attention by nurses. This phenomenon cuts across the entire health work force, and very often scares patients/clients out of the hospital who now seek medical care outside the hospital. The resultant effect of these alternatives is dangerous health complications and loss of lives.

Evidence abound within the health system that is suggestive that a patient's health can improve or that a patient can cope better with illness when he or she is valued and treated with respect by nurses. (Adib-Hajbaghery and Aghajani 2015, Ferri, Muzzalupo and Lorenzo 2015, John, 2016, Tadd, Hillman, Calnan, Calnan, Bayer and Read 2011). Upholding and respecting patients dignity has a central place in the caring profession (Nursing). Baillie, (2011) asserted that preserving human dignity is integral to the caring mission of nursing. Nurses have the responsibility to maintain and respect a patient's dignity and uniqueness after he/she lacks the ability to do so. Therefore patients' perceived satisfaction with respect for their dignity by nurses is an important indicator to evaluate quality nursing care provided. 
Dignity is a basic human right for all individuals, and health care organizations should pay attention to this universal need (Adib-Hajbaghery and Aghajani 2015). The word dignity is derived from two latin words; 'dignitas' which means merit, implying that one has to achieve something to be dignified; and 'dignus' which means worth, suggesting a quality that renders something valuable (Ferri, et al 2015). The Royal College of Nursing (RCN) (2008) proposed a definition of dignity to imply 'Concern with how people feel, think and behave in relation to the worth or value of themselves and others'. Williams (2012) pointed out that Florence Nightingale's appropriate professionalism was 'whatever served not only the physical aspect of health but the dignity of those being cared for'.

The need to preserve the dignity of patients is included in most policy statements for health professionals and the significance of patients' dignity is also reflected in various professional nursing bodies' code of conduct (Lin 2013). The International code of ethics (the ICN code of ethics) adopted in 1953, guides the practice of nursing globally. This stipulates that nursing care is unrestricted irrespective of age, color, creed, culture, disability or illness, gender sexual orientation, nationality, politics race and social status (John, 2016). The ICN proposed code of ethics serves as a guide for action based on social values and needs; it has four elements which outlines standard of ethical conduct for nurses to include: 1) 'Nurses and people', which represents nurses respect for patients race, age, religion, sickness or handicap, gender, political, social and economic status; 2) 'Nurses and practice' suggesting that nurses may offer competent care by enhancing their professional care abilities; 3) Nurses and the profession', which indicates that nurses should develop professional knowledge based on research; 4) 'Nurses and co-workers' which refers to nurses acting as mediators amongst various health care professional groups, protecting patients and their families if endangered by co-workers (Monookian 2014). Furthermore, The Universal Declaration of Human Rights recognizes the 'inherent dignity'; the equal and unalienable rights of human beings, this inherent dignity forms basis of the concept of a person and the fundamental dignity and equality of all human beings, which patients' right is derived from (WHO, 2015). Treating someone with dignity is to treat him or her as being worth, in a way that is respectful of him or her as a valued individual.

Tadd, et al (2011), opined that care is largely task based and reactive to patients request for assistance in a state of dependence; and that, key elements of dignified care, include: respectful communication; information to aid decision making; and focusing on the individual. Undignified care was seen as care which renders individuals invisible, depersonalizes and objectifies a person, abusive or humiliating, narrowly focused and disempowers the individual. Therefore quality of care is dependent not only on the care received, but also on the way the care is delivered. One such ways is by nurses' communicating effectively with care recipients (Ferri, et al 2015).

USA Department of Health and Human Services (2011) stated that good medical care strongly depends upon effective communication between patients and provider, while ineffective communication can lead to improper diagnosis, delayed or improper medical treatment. In like manner ineffective communication between nurses and patients can lead to wrong nursing diagnosis and improper nursing care. Respect for patient's dignity by nurses through effective communication fosters a therapeutic relationship. In Ferri et al (2015) study, participants (patients') acknowledged that respecting their dignity through effective communication can promote not only a greater emotional comfort or a sense of well-being but facilitate healing process and process of recovery. Roy (2014), affirmed that undignified care is observed when nurses communicate with patients impolitely, for instance speaking too loudly concerning patients private matters, not giving them sufficient time to tell their stories, failing to listen and involve patients in their care. Ability to provide patients with adequate information, explain, listen and empathize can help them make informed decisions which can have a profound effect on biological and functional health outcomes as well as patient satisfaction and experience with care (Makaryus \& Friedman, 2005).

Patients' participation in decision-making in nursing care is regarded as a prerequisite for good clinical practice. However, the study of Florin, Ehrenberg and Ehnfors (2008) on Clinical decisionmaking: predictors of patient participation in nursing care; revealed that patients' preferences for participation differed considerably and are best elicited by assessment of the individual patient. Content analysis showed that conditions for patient participation occurred when information was provided based on individual needs and accompanied by explanations; when the patient was regarded as an individual; when the patient's knowledge was recognized; and when the patient made decisions based on knowledge and needs, or performed self-care. Tadd, et al (2011) examined 'Dignity in practice; an exploration of the care of older adults in acute hospitals' identified some behaviors of 
nurses which discouraged patient's participation in decision making, to include: abuses, objectification and depersonalization of patients. According Sekimo, et al (2004) patients' preferences for involvement in treatment and decision making in Japan, showed that majority of Japanese patients have positive attitudes towards participation in medical decision making if they are fully informed. This shows a link between effective communication and decision making. Nurses have a professional responsibility to act in a way that patients can participate and make decisions according to their own values from an informed position. Access to knowledge by patients' and preferences for participation is of great value for nurses in the care process. Patients' should be well informed to enable them participate in making decision with an understanding of the consequences of their decision; they should be assessed and treated as unique individuals.

Individual differences among patients, in terms of their health, illness and needs emphasize the necessity of individualized care (Suhonen, Papastavrou, Ffstathiou,Tsangari, Jarosova, and LeinoKilpi et al 2012 ). Also Gurdogan, Findik and Arslan, (2015) asserted that variations in patients experiences, expectations and problems necessitates the consideration of patients perception in the individualization of care. Individualized care or patient centered care is concerned with the adjustment of nursing care according to patient's beliefs, values, emotions, thoughts, preferences, experiences and perceptions (Suhonen, Papastavrou, Efstathiou, Tsangari, Leino-Kilpi, Patiraki, Karlou, Balogh, and Merkouris 2011). For Gurdogan et al, (2015), the concept of individualized care addresses the honor, uniqueness, integrity of the patients and the ethical and moral values related to the consideration and protection of patients' rights. Core principles of individualized care provide a foundation for dignity and respect, information sharing, participation and collaboration between nurses and patients (The British Columbia Patient Centered Care Framework, 2015).

It is important to note that the patient level of individualism is a primary factor in his perception of the quality of nursing care. Therefore, individualized care is broadly associated with the perception, experiences and feeling of the patient who has been provided with care (Acaroglu and Sender, 2012). Gurdogan et al, (2015) assessed 'Patients' Perception of Individualized Care and Satisfaction with Nursing Care Levels in Turkey; the result showed that patients were aware of individualized care and that individualized care increased the level of a patient's satisfaction with nursing services. They recommended that nurses should care for patients as unique individuals, provide care specific to a patient, to support individualized care which turn influenced patient' perception of nurses' respect for their dignity.

Rasooll, Zamanzadeh, Rahmani and Shahbazoor (2013) highlighted on 'Patients Point of View about Nurses Support of Individualized Nursing Care in Training Hospital', and affirmed that nurses' were not committed to rendering individualized care and this affected patient's satisfaction with nursing care. They recommended that nursing care planners should pay more attention to the aspects of nursing that supports Individualized care and patient satisfaction.

A review of researches in the field of maintaining patients' dignity showed that nearly all researches conducted were in European countries while there is paucity of research in this regard in Nigeria. Also very little research exist on patients' perception of nurses' respect for their dignity in Cross River State, this informs the need for this study. Examining patients' perception of nurses' respect for their dignity will provide information to nurse educators and clinicians in the training, planning and practice of care.

It is also believed that respecting patients' dignity through effective communication, patients' involvement in decision making and freedom to choose through informed knowledge will facilitate patients' recovery.

The most important responsibility of nurses is to practice nursing care by respecting the dignity of their patients (Lands and Suhonen, 2009 and Jacobson, 2009). Therefore this study seeks to examine patients' perception of nurses' respect for their dignity during hospitalization in UCTH, Calabar.

\subsection{Purpose of the Study}

The purpose of the study was to examine factors influencing patients' perception of nurses' respect for patients' dignity during hospitalization in University of Calabar Teaching Hospital (UCTH), Nigeria. 


\subsection{Specific Objectives Were}

- To ascertain patients' view of nurses 'effective communication as a factor in nurses respect for patients' dignity

- To determine whether patient perceive their participation in decision-making as a factor in nurses respect for patients' dignity

- To determine whether patients perceive individualized care as a factor in nurses' respect for their dignity in UCTH, Calabar.

\subsection{Hypotheses}

- There is no significant relationship between nurses' effective communication and patients' perception of nurses' respect for patients' dignity in UCTH, Calabar.

- There is no significant relationship between patient participation in decision making and patients' perception of nurse's respect for their dignity in UCTH, Calabar.

\section{MeTHODOLOGY}

\subsection{Research Design}

The research design adopted for this study was descriptive survey

\subsection{Research Setting}

The study site was University of Calabar Teaching (UCTH), Calabar. UCTH is a tertiary hospital located in Calabar Municipality which is one of the two local Government areas in Calabar. The hospital serves as training centre for all cadres of health personnel, and as a referral centre for the state. The research was carried out in the male and female medical ward, male and female surgical ward and male and female orthopedic wards.

\subsection{Study Population}

The target population consisted of patients' who were hospitalized from November, 2015 to January, 2016 in the six wards. The accessible population consisted of 112 patients. Eighty eight (88) patients were selected through purposive sampling. Inclusion criteria was : hospitalized for up to one week and beyond, at least 20 years old, not too ill patients and conscious patients, able to speak English and willing to participate in the study. Patient with less than one week stay, unconscious, and very sick patients, those not able to communicate in English and those not willing to participate were excluded.

\subsection{Research Instrument}

A self developed structured questionnaire which consisted of four sections was used. Section A contained respondents' socio-demographic data, Sections B, C and D contained items that highlighted patients perception of dignity by evaluating three main topics 'effective communication', ' participation in decision making' and 'individualized care'. Cronbach alpha coefficient obtained ranged between $0.76-0.81$.

\subsection{Data Collection}

The copies of the questionnaires were administered face to face to the patients with the aid of two research assistants, and on the spot collection, of the 88 only 84 questionnaire were valid while 4 was not properly completed

\subsection{Ethical Consideration}

An official permission was obtained from the institution. Informed consent was obtained from the subjects who participated in the study. Before administering the questionnaire the researcher explained to each participant the purpose and significance of the study as well as participants right to withdraw from it at any time without any impact on clinical treatment. Anonymity and confidentiality were assured and their decision to participate voluntarily was respected.

\subsection{Data Analysis}

Descriptive and inferential statistics were used to analyze data. 
Factors Influencing Patients Perception of Nurses Respect for Their Dignity in a Public Hospital in Calabar, Nigeria

\section{RESULTS}

Table1. Socio-demographic characteristics of respondents in public hospital in Calabar, Nigeria $n=84$

\begin{tabular}{|c|c|c|}
\hline Variables & Frequency & Percentage (\%) \\
\hline \multicolumn{3}{|l|}{ Age in year: } \\
\hline 20-29 years & 28 & 33.33 \\
\hline $30-39$ years & 26 & 30.95 \\
\hline 40-49 years & 14 & 16.67 \\
\hline 50 years \& above & 16 & 19.05 \\
\hline Total & 84 & 100 \\
\hline \multicolumn{3}{|l|}{ Gender } \\
\hline Male & 30 & 35.71 \\
\hline Female & 54 & 64.29 \\
\hline Total & 84 & 100 \\
\hline \multicolumn{3}{|l|}{ Marital status } \\
\hline Married & 47 & 55.95 \\
\hline Single & 31 & 36.90 \\
\hline Divorced & 2 & 2.38 \\
\hline Widowed & 4 & 4.76 \\
\hline Total & 84 & 100 \\
\hline \multicolumn{3}{|l|}{ Educational qualification } \\
\hline SSCE & 21 & 25.0 \\
\hline B.Sc & 34 & 40.48 \\
\hline Master' & 12 & 14.29 \\
\hline Ph.D & 2 & 2.38 \\
\hline Others & 5 & 5.95 \\
\hline Total & 84 & 100 \\
\hline \multicolumn{3}{|l|}{ Period of hospitalization } \\
\hline 1-4 weeks & 42 & 50.0 \\
\hline 5-9 weeks & 26 & 30.95 \\
\hline 10-14 weeks & 8 & 9.52 \\
\hline 15 weeks \& above & 8 & 9.52 \\
\hline Total & 84 & 100 \\
\hline
\end{tabular}

Most respondents 54(64.29\%) were between ages20-30years, majority, 54(64.29\%) were females, most respondents $47(55.99 \%)$ were married, while $48(57.15 \%)$ had university education, and all respondents had above I week hospitalization

Table2. Influence of nurses effective communication on patients perception of nurses' respect for their dignity in a public hospital in Calabar, Nigeria.

\begin{tabular}{|l|c|c|c|c|c|}
\hline \multicolumn{1}{|c|}{ Items } & \multicolumn{3}{c|}{ Responses } & Total \\
\cline { 2 - 5 } & Yes & $\%$ & No & $\%$ & \\
\hline $\begin{array}{l}\text { During discussion of personal matters did nurses ensure } \\
\text { your sufficient privacy? }\end{array}$ & 66 & $78.6 \%$ & 18 & $21.4 \%$ & 84 \\
\hline $\begin{array}{l}\text { Did nurses communicate with you using a kind and friendly } \\
\text { warm tone? }\end{array}$ & 52 & $61.9 \%$ & 32 & $38.1 \%$ & 84 \\
\hline Did nurses give you sufficient time to tell your history? & 68 & $80.9 \%$ & 16 & $19.0 \%$ & 84 \\
\hline $\begin{array}{l}\text { Did nurses provide enough information on diagnostic and } \\
\text { therapeutic procedures that you needed? }\end{array}$ & 66 & $78.6 \%$ & 18 & $21.4 \%$ & 84 \\
\hline Did nurses listen to you attentively? & 69 & $82.1 \%$ & 15 & $17.9 \%$ & 84 \\
\hline
\end{tabular}

The result presented in table 2 shows that majority of the patients agreed that nurses use polite speech $(78.6 \%)$ nurses obtain informed consent $(80.9 \%)$, they are given update on their treatment $(78.6 \%)$ and nurses listen to them attentively $(82.1 \%)$. With regards to the use of non-verbal communication, $61.9 \%$ agreed that many $38.1 \%$ said no. 
Table3. Influence of patients participation in decision-making on their perception of nurses' respect for their dignity in a public hospital in Calabar, Nigeria.

\begin{tabular}{|l|c|c|c|c|c|}
\hline \multicolumn{1}{|c|}{ Items } & \multicolumn{3}{c|}{ Responses } & Total \\
\cline { 2 - 4 } & Yes & \% & No & \% & \\
\hline $\begin{array}{l}\text { Did nurses involve you in your health program and allow } \\
\text { you to make decisions in this regard? }\end{array}$ & 52 & $61.9 \%$ & 32 & $38.1 \%$ & 84 \\
\hline $\begin{array}{l}\text { Did nurses ever ask you for your own suggestion each time } \\
\text { they were to take a decision about you? }\end{array}$ & 47 & $55.9 \%$ & 37 & $44.0 \%$ & 84 \\
\hline $\begin{array}{l}\text { Did nurses ask for your permission before performing care } \\
\text { procedures on your body? }\end{array}$ & 49 & $56.3 \%$ & 35 & $41.7 \%$ & 84 \\
\hline $\begin{array}{l}\text { Did nurses give you enough information about your } \\
\text { condition to enable you make decision? }\end{array}$ & 50 & $59.5 \%$ & 34 & $40.5 \%$ & 84 \\
\hline $\begin{array}{l}\text { Did nurses allow you perform daily activities if you were } \\
\text { able to perform them by yourself at the time you wanted? }\end{array}$ & 57 & $67.9 \%$ & 27 & $32.0 \%$ & 84 \\
\hline
\end{tabular}

Table 3 Reveals that $52(61.9 \%)$ patients confirmed that they are involved in decision-making while $32(38.1 \%)$ said they are not. $47(55.9 \%)$ of the respondents said they are allowed to make suggestions while $37(44.1 \%)$ said no. in the aspect of nurses' value for patients' opinion, 49(58.3\%) said yes while 35(41.7\%) said no. With regards to full disclosure of information and permission for consent, $50(59.5 \%)$ and $57(67.9 \%)$ respectively said yes while $43(40.5 \%)$ and $27(32.1 \%)$ responded no.

Table4. Influence of individualized care on patients' perception of nurses' respect for patients' dignity in a public hospital in Calabar, Nigeria.

\begin{tabular}{|c|c|c|c|c|c|}
\hline \multirow[b]{2}{*}{ Items } & \multicolumn{4}{|c|}{ Responses } & \multirow[t]{2}{*}{ Total } \\
\hline & Yes & $\%$ & No & $\%$ & \\
\hline $\begin{array}{l}\text { Did nurses ever refer to you using respectful language without } \\
\text { calling you by your name? }\end{array}$ & 26 & 30.95 & 58 & 69.05 & 84 \\
\hline $\begin{array}{l}\text { Did nurses treat you with respect without using excessive } \\
\text { familiar manner? }\end{array}$ & 62 & 73.81 & 22 & 26.19 & 84 \\
\hline Did you have privacy to use the bathroom? & 68 & 80.95 & 16 & 19.05 & 84 \\
\hline $\begin{array}{l}\text { When discussing you with other health care professionals, did } \\
\text { nurses refer to you using your name rather than the number of } \\
\text { your bed? }\end{array}$ & 38 & 45.24 & 46 & 54.76 & 84 \\
\hline $\begin{array}{l}\text { While undergoing nursing procedures which required exposure } \\
\text { of private parts of your body was your bed properly screened or } \\
\text { your door closed by nurses? }\end{array}$ & 78 & 92.86 & 6 & 7.14 & 84 \\
\hline
\end{tabular}

The result presented in table 4 shows highest percentage of negative responses 58(69.05\%) in terms of nurses using respectful language on patients and 46(54.76\%) negative responses in terms of nurses referring to patient using name rather than bed number while discussing patient with other health care professionals. The other three items had high percentage of positive responses.

Table5. Contingency chi-square analysis of the relationship between nurses' effective communication and patients ' perception of nurses' respect for patients' dignity in a public hospital in Calabar, Nigeria.

\begin{tabular}{|l|c|c|c|c|c|c|}
\hline \multicolumn{1}{|c|}{ Options } & $\mathbf{O}$ & $\mathbf{E}$ & $\mathbf{0 - e}$ & $\frac{(\mathbf{o - e})^{\mathbf{2}}}{\mathbf{E}}$ & Cal. $\mathbf{X}^{\mathbf{2}}$ & df \\
\hline Yes & 52 & 43.68 & 8.32 & 2.585 & 23.216 & 1 \\
\hline No & 32 & 26.88 & 5.12 & 1.874 & & \\
\hline
\end{tabular}

* Significant at $0.05 ; d f=1 ;$ Critical $X^{2}=9.49$

Table 5 shows that the calculated $\mathrm{x} 2$ value of 23.216 is higher than the critical $\mathrm{x}^{2}$ value of 9.49 at 0.05 level of significant with 1 degree of freedom. Null hypothesis is rejected, implying that there is a significant relationship between nurses' effective communication and patients' perception of nurses' respect for patients' dignity in University of Calabar Teaching Hospital.

Table6. Contingency chi-square analysis of the relationship between patients' participation in decision making and patients' perception of nurses' respect for patients' dignity in a public hospital in Calabar, Nigeria.

\begin{tabular}{|l|c|c|c|c|c|c|}
\hline \multicolumn{1}{|c|}{ Options } & O & E & o-e & $\frac{(\mathbf{o - e})^{\mathbf{2}}}{\mathbf{E}}$ & Cal. $\mathbf{X}^{\mathbf{2}}$ & df \\
\hline Yes & 39 & 31.412 & 7.58 & 1.829 & 12.734 & 1 \\
\hline No & 45 & 36.648 & 8.352 & 1.903 & & \\
\hline
\end{tabular}

* Significant at 0.05; $d f=1$; Critical $X^{2}=9.49$ 
Table 6 shows that the calculated $\mathrm{x} 2$ value of 12.734 is higher than the critical $\mathrm{x}^{2}$ value of 9.49 at 0.05 level of significance with 1 degree of freedom. Null hypothesis is rejected. Therefore, there is a significant relationship between patients' participation on decision making and patients' perception of nurses' respect for patients' dignity.

\section{DISCUSSION OF FINDINGS}

This study which evaluated patients' perception of nurses' respect for their dignity during hospitalization in UCTH highlighted that dignity was quite but not completely maintained according to the standards expected by patients. This agrees with the conclusion made by (Ferri, et al 2015). In the section of patients' perception of nurses' respect for their dignity through effective communication, the percentage of positive answers evidenced in 'attentive listening 69(82.1\%)', 'given sufficient time to tell self story $68(80.9 \%)$ ' 'Provide enough information on diagnostic and therapeutic procedures that you needed $66(78.6 \%)$ ' were more perceived as respect for dignity. The results support the findings of Jacobson (2009) that effective communication influenced patients' perception of nurses' respect for their dignity. However, 'using kind, warm, low tone to communicate with patients received the lowest positive percentage of 52(61.9\%) responses. This was rather discouraging given the fact that communication with warmness ensures rapport and establishes a therapeutic relationship.

Regarding patients' participation in decision making 'Asking patient for own suggestion' and 'asking for patients' permission before performing any procedure on them' received the lowest percentage of positive responses, $47(55.9 \%)$ and $49(56.3 \%)$ respectively. This suggest that seeking for and respecting patients opinion were insufficient as highlighted by Sekimo et al (2004). 'Allowing patient to perform daily activities if able received the highest percentage of positive responses of 57 (67.9\%). It could be inferred that since nurses always complain of work load they may be very willing to relinquish some activities to patients and their relatives if they indicate interest to do so. 'Giving patients enough information to enable them make informed decision and involving patients in their health programs received average positive answers of 50( 59.5\%) and $52(61.9 \%)$ respectively. This affirms the conclusion of Sekimo et al that patients have positive attitudes towards participation in decision making if they are fully informed. Although Eylem, Ummu, Buket, (2015) opined that today patients increasingly desire, to have a voice in decisions about their condition and to participate in their own care, the average percentage positive responses observed in these items could be associated with the findings of Florin, Ehrenberg and Ehnfors (2008) that patients had preferences for participation in decision making which differed considerably and are best elicited by assessment of the individual patient.

For individualized care 'using respectful language on Providing privacy is, "nurses referring to patient using name rather than bed number while discussing patient with other health care professionals' received highest percentage negative responses of 58 (69.05\%) and 46( 54.76\%) respectively, indicating that dignity in these areas was not respected. This is as affirmed in the study of Lands and Suhonen (2009), that consideration of individualized differences during nursing interventions have been neglected by nurses. To this, they advised that nurses should apply flexibility in different conditions and consider the reality of each patient's uniqueness. They further stated that nursing interventions should be individualized and that various interventions should be used for different patients. 'Providing privacy for care that exposes any body part' and 'having privacy to use bathroom' had higher percentage of positive responses 78 (92.86\%) and 68(80.95\%). Implying that dignity in these areas was more respected. Avoidable body exposure can be considered as an important aspect of dignity (Ferri et al 2015, Baillie, 2009). These findings can also be associated with the training that nurses receive in their various training schools. Generally much emphasis is laid on maintaining a patient's privacy during any given procedure. It encouraging because it implies that these rules are still being greatly upheld by nurses. Gurdogan et al, (2015), had asserted that maintaining privacy gives patients a sense of honor, uniqueness, moral value.

Further result showed a statistically significant relationship between nurses effective communication and patients positive perception of their dignity with cal $\mathrm{x}^{2}=23.216$, crit $\mathrm{x}^{2}=9.49$, df $1, \mathrm{P}<0.05$, and between patients participation in decision making and their perception of nurses respect for their dignity with cal $\mathrm{x}^{2}=12.734$, crit $\mathrm{x}^{2}=9.49$, df $1 \mathrm{P}<0.05$. 
Indicating that the more effective nurses' communication is with patients and the more participation of patients in taking informed decisions for their care, the more positive their perception of nurses' respect for their dignity will be and vise versa (Gurdogan, et al 2015). This findings show that patients perception of nurses respect for their dignity has an effect with satisfaction with nursing care and that effective communication, patients participation in decision making increased satisfaction with nursing care. Nurses' practice with respect for patients' dignity is important in obtaining positive patient result.

\section{CONCLUSION AND RECOMMENDATIONS}

Patients were quite but not fully satisfied with nurses' respect for their dignity. Secondly, nurses' effective communication with patients and patients' participation in decision making had positive significant correlation with patients' perception of nurses' respect for their dignity. This implies that Nurses' respect for patients' dignity is a strong positive factor that enhances patients' positive perception of their dignity, promote not only greater 'emotional comfort' or 'a sense of well being' but can also facilitate their recovery. Promoting dignity demands attention in nursing policy making and ethical educational programs. It can foster nurses' professional knowledge, behavior and responsibility. It is recommended that nurses' care for patients as unique individuals provide them with adequate information in a respectable manner that will enable them to make informed decisions and take responsibility of the decisions. Nurses should look beyond the physical presentation of the patients and seek to understand the feeling and experiences of the patient.

\section{Implication for Nursing Education}

This result calls upon nurse educators and clinical instructors to strengthen nursing professional training in the delivery of patient centered care using the nursing process. The individualized care model underscores essential features such as reflective listening and empathy as a way of nurses' response to a patient's unique needs, values and preferences of individual patients. Communication training for nursing students should be given far more attention throughout the training process than other management tasks.

\section{REFERENCES}

Whitehead, J and Wheeler, H. (2008) Patients experience of privacy and dignity, a literature review. Br Journal of Nursing 17: 381-385

Adib-Hajbaghery, M. \& Aghayari, (2015). M Patient dignity in nursing. Nursing and midwifery studies. 4(1): e22809Retrieved $2^{\text {nd }}$ March, 2016 from http//www.ncbi.nlm.nih.goo/pmc/articles/ pmc43/752.7/.

John, M. E (2016) Value Added Nursing Care: Best Practice or Wishful thinking? Inaugural Lecture; University of Calabar.

Tadd, W., Hillman, A., Calnan, S. Calnan, M., Bayer, T. \& Read, S. (2011). Dignity in practice: An exploration of the care of older adult in acute NHS Trusts. Retrieved from www.bgs.org-uk/pdfcmf/referenes/radd_dignity_in_practice.pdf.

Baillie, L and Gallagher, A. (2011), Respecting Dignity in care in diverse care settings: strategies of UK nurses. International Journal of Nursing practice 17; 336-341

Royal College of Nursing (2011). Dignity in health care, Retrieved $12^{\text {th }}$ November, 2016 from http//www.rcn.org.u/development/practice/ cpd_online_learning/dignity_in_health_care.

Williams, R.A (2012), a passion for human dignity. NIGH-Nightingale Initiative for global health declaration campaign-creating a healthy world together,www.nightingaledeclaration.net, accessed 8 June 2016.

Lin, Y.P., Tsai, Y. F., and Chen, H. F. ( 2011) Dignity in care in the hospital setting from patients' perspective in Taiwan: a descriptive qualitative study. J Clin Nurs 20: 794-801

Manookian, A., Cheraghi, M. A. \& Nasradi, A. (2014). Factors influencing patients' dignity. SAGE Journals; Vol. 21 No 3.323-334.

World Health Organization (2015). Patients' rights. Genomic resource centre. Retrieved $2^{\text {nd }}$ March, 2016 from www.who.int/genomics/ public/patient right/en/. 
United State of America, Department of Health and Human Services (2011). Effective communication in hospital. Retrieved $4^{\text {th }}$ Nov.2015 from http//www.bhs.gov/ocr/civil rights/resources/ special topic/hospital.

Roy, J. A. (2014). Reconnecting nursing and patients dignity: An integrative review. University of British Columbia. Retrieved $16^{\text {th }}$ October, 2015 from circle.ubc.ca/bit stream/handle/2429/ 50261/ubc_204_November_Roy_Jennifer.pdf.

Makaryus, A. N, \& Friedman, E. A. (2005). Patients' understanding of their treatment plans and diagnosis at discharge. Mayo clinic proceedings 80(8), 991-994.pubmed.

Sekimo , A., Asai, O., Nishigaki, E., Fukui, T.,Shimbo T., and Imanaka, Y (2004) on Patients' preferences for involvement in treatment decision making in Japan.

Suhonen, R., Efstathiov, G., Tsangari, H., Jarosova, D Leino-kilpi, H., Patiraki, E., Karlov, C., Balough, Z., Merkouris, A. (2012). Patients' and nurses perception of individualized care: an international comparative study. Journal of Clinical Nursing(2012) 21(7-8):1155-67

Gurdogan, E. P., Findik, U. Y. \& Arslan, B. K. (2015). Patients' perception of individualized care and satisfaction with Nursing Care Level in Turkey. International Journal of Caring Sciences' Vol. $8: 2,369$.

Suhonen, R., Papastavrou, E, Ffstathiou, G., Tsangari, H, Jarosova, D, Leino-Kilpi, H, et al (2012) Patient satisfaction as an outcome of individualizes nursing care. Scand J Caring Sci 26(2): 37280

The British Columbia Patient Centered Care Framework (2015) nd. Retrieved $17^{\text {th }}$ January, 2015 from www.health gov:bc.Ca/../pt-centered care-framework. Ministry of Health, Feb. 1, 2015.

Acaroglu, R. \& Sender, M. (2012)The seals for assessment of individualized care. Journal of Istanbul University Florence Nightingale Nursing School. 20 (1): 10-16.

Rasooll, Zamanzadeh, Rahmani and Shahbazpoor (2013). Patient Point of View about Nurses Support of Individualized Nursing Care in Training Hospitals Affiliated with Tabriz University of Medical Science. Journal of Caring Science: 2(3), 203-209.

Land L Suhonen R. (2009) Orthhorpaedic and Trauma patient perception of Individualized care. International Nursing Review 56(1):131-137

Jacobson, N. (2009). A taxonomy of dignity: A grounded theory study. BMC International Health \& Human Right. Retrieved $18^{\text {th }}$ August 2015 from. http://creativecommons.org/licenses/by/2.0

Baillie, L. (2009). Patient dignity in an acute hospital setting: A case study. International Journal for Nursing Practice, 46:23-27.

\section{AUTHORS' BIOGRAPHY}

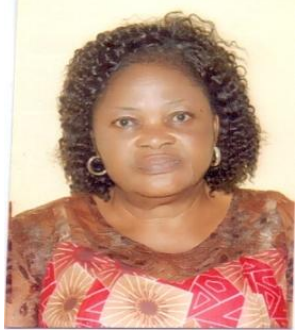

Regina E. Ella, is a Nigerian Registered Nurse/Midwife with B. Sc Nursing; M.Ed and Ph. D with specialization in Educational Administration and Planning. She currently works as a senior lecturer with the University of Calabar. She has worked with the Cross River State Government as Secretary and Coordinator of the State Agency for Aids Control; as Palliative Care Advisor with CEDPA on HIV/AIDS Positive Living Project; Consultant trainer on HIV/AIDS Palliative Care with MSH. She is a Master trainer of trainers with CEDPA on HIV/AIDS Palliative Care. Her areas of interest are Nursing Education and HIV/AIDS. Dr Ella is a Fellow of The West Afriacn College Of Nursing (WACN). A member of International Council for Nurses, member of the Honor society of Nursing (STTI) LAMDA Nigerian Chapter, and Member of American Public Health Association (APHA)

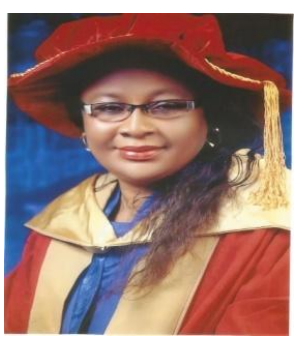

Patience Edoho Samson-Akpan, is a Registered Nurse/ Midwife and nurse educator. She obtained her BSc (Nursing) from University of Ibadan; Master's Degree in Public Health from University of Calabar, Nigeria and $\mathrm{PhD}$ in Health Education from the same University. She is currently an Associate Professor and a former Head of Department of Nursing Science in University of Calabar, Nigeria. She is a member of West African College of Nursing (FWACN, 2009); International Council of Nurses (ICN) etc. She has several awards in her honour such as "Best Academic Student Award from 1987-1981" School of Nursing, Calabar. She is a member of She has authored books and published many articles in local and international journals 


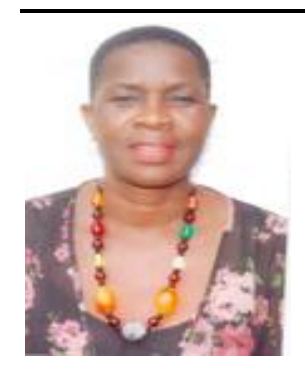

Mary Achi Mgbekem (PhD), is faculty member of the Department of Nursing Science, Faculty of Allied Medical Sciences, University of Calabar (Unical), She holds a PhD in Human Nutrition, MSN, M.Sc (H/N) and B.Sc Nursing. She has served both the State and National Governments in Nigeria in various hospitals. She served as volunteer in Kasama School of Nursing Zambia. She joined the University of Calabar in 2000 as Assistant lecturer and has risen to the position of Senior Lecturer. She has served in various committees in the University and has 25 publications in Local and international Journals to her credit. She has attended professional conferences locally and internationally. She is a Fellow of the West African College of Nursing. She is the current chairperson of the nutrition Society of Nigeria, Cross River State Branch and immediate past President of Rotary Club International, Calabar-Unical. She is the current Head of Department.

Grace David Edet, is a Registered Nurse /Midwife. She has currently completed her BNsc degree in Department of Nursing Science, University of Calabar. She has served in different capacities in the clinical setting with over 10 years of experience. She currently works at as a Senior Nursing Officer with the University of Calabar Teaching Hospital, (UCTH) Cross River State, Nigeria. She is a member of the National Association of the Nigerian Nurses and Midwives, UCTH branch. 